\title{
Sample size determination in medical researches
}

\author{
$\underline{\text { Roshani Daem }^{1}}$, Nouri Bijan ${ }^{2}$, Moradi Masoud ${ }^{3}$ \\ 1.Associate Proffesor, Social Determinants of Health Research Center, Research Institute for Health Development, Kurdistan \\ University of Medical Sciences, Sanandaj, Iran. (Corresponding author) Email:daemroshani@gmail.com Tel: \\ +989128007042 ORCID ID: 0000-0003-4746-1114 \\ 2.Assistant Proffesor, Social Determinants of Health Research Center, Research Institute for Health Development, Kurdistan \\ University of Medical Sciences, Sanandaj, Iran. ORCID ID: 0000-0003-0064-0094 \\ 3. Vice Chancellor for Research and Technology, Kurdistan University of Medical Sciences, Sanandaj, Iran. ORCID ID: \\ 0000-0002-7813-9518
}

\begin{abstract}
Background and Aim: One of the problems of the researchers at the start of the research is estimation of sample size and selection of appropriate sample of the population. A small sample size can damage research credibility and lead to loss of money and waste of time. In contrast, a large sample size can lead to increased workload, cost, and lack of proper feedback. The purpose of this study was to evaluate the sample size in various medical studies.

Materials and Methods: In this study, after determining the types of studies, various sources (books, journals, articles, etc.) were searched and different sampling methods based on the type of variable, were determined and classified on the basis of the corresponding formulas. Among the different methods we extracted the best formulas and methods on the basis of the type of study and other important and confounding factors.

Result: Various studies have shown that several factors affect sample size including effect size, power of the test, significance level, maximum error of measurement, ratio, and variation of the trait. In this study, it was shown that in regression models, the effect of the correlation coefficient between variables should be controlled and the sample size should be estimated by considering and balancing the generated dispersion amount. Also, the size of the effect of the most important indicator and the test power is strongly influenced by the sample size.

Conclusion: In most similar studies, it has been shown that for estimation of the effective and valid sample size, the error rate should be low and the test power should be high, and also the effect values, level of significance and dispersion, and the correlation between the variables should be controlled.
\end{abstract}

Keywords: Sample size, Biomedical researches, Power

Received: July 7, $2019 \quad$ Accepted: July 11, 2020

How to cite the article: Roshani Daem, Nouri Bijan, Moradi Masoud. Sample Size Determination In Medical Researches.SJKU. 2020;25(5):104-112.

Copyright (C) 2018 the Author (s). Published by Kurdistan University of Medical Sciences. This is an open access article distributed under the terms of the Creative Commons Attribution-Non Commercial License 4.0 (CCBYNC), where it is permissible to download, share, remix, transform, and buildup the work provided it is properly cited. The work cannot be used commercially without permission from the journal 


\section{تعيين حجم نمونه در مطالعات علوم يزشكى}

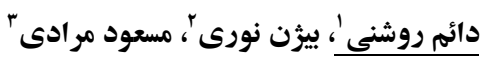

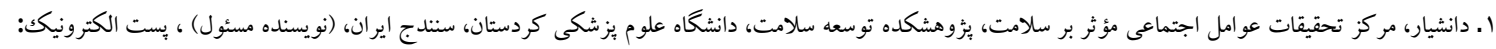
........r-FVF9-111fF: daemroshani@gmail.com

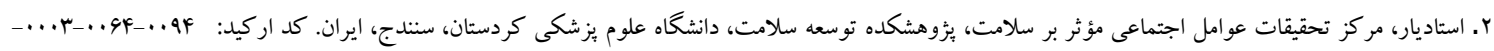

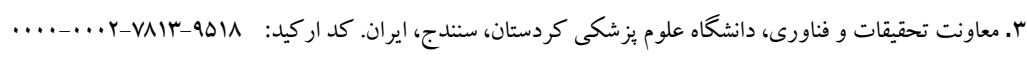

جكيده زمينه وهدف: يكى از مسائلى كه اكثرمحققين در شروع ئزوهش خودبا آن سرو كار دارند، موضوع بر آوردحجم نمونه و انتخاب يكك نمونه مناسب از جامعه مورد مطالعه است. بر آورد يائين حجم نمونه سبب آسيب به اعتبار بثروهش و هـدر رفت هزينه و زمـان مى شود در مقابل بيش بر آورد آن باعث افزايش حجم كارى، هزينه و عدم بازخورد مورد انتظار خواهد شدهــدف از ايـن يـزوهش تعيين حجم نمونه در مطالعات مختلف علوم يزشكى مى باشد. مواد و دوش ها: در اين مطالعه ، يس از تعيين انواع مطالعات، در منابع مختلف داخلى و خارجى (كتابها، مجله هـا، مقـالات و ...) جستجو انجام شد و روشهاى مختلف تعيين حجم نمونه بر اساس نوع متغيـر، همـراه بـا فرمولهـاى مربوطه استخراج و دسـته بنــى

شدند. از بين روشهاى مختلف با توجه به نوع مطالعه و ساير عوامل مهم و تاثير گذار، بهترين فرمول و روش استخراج شده است. يافته ها: ئزوهش هاى مختلف نشان داده اند كه معيار هاى متعددى بر روى حجم نمونه تاثير مى كذارند كه شامل اندازه اثر، تـوان آزمون، سطح معنى دارى، حداكثر خطاى اندازه گيرى، نسبت و براكندگى صفت مورد بررسى مى باشند. در اين مطالعه نشـان داده

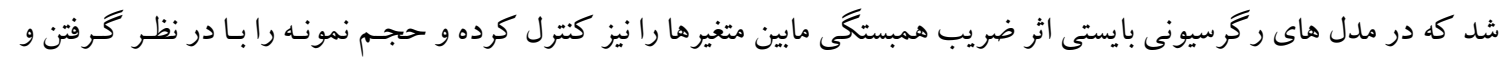

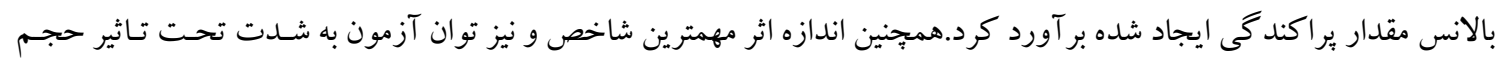
نمونه مى باشد. نتيجه كيرى: در بيشتر مطالعات مشابه استباط شده است كه جهت بر آورد حجم نمونه اى كاراو معتبر بايستى مقدار خطا يـائين و توان آزمون بالا بوده همجينين مقادير اثر، سطح معنى دارى و بر اكندگى و همبستخى بين متغيرها كنترل شوند. كليد وازه ها :حجم نمونه، مطالعات علوم يزشكى، توان آزمون

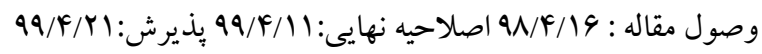


برسند، يعنى جـايى كـه انجـام مصـاحبه باعـث افزوده شـدن

اطلاعات جديد نشود ، ادامه بيدا مى كند (4). مطالعات مختلفى بـراى محاسـبه حجــم نمونــه انجـام شـــه اسـت و فرمولهاى متعددى بـراى تعيـين حجـم نمونسه وارائـه شده است. در اين فرمولها ســطح معنى دارى (م) ، تـــوان

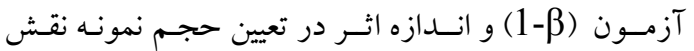
دارند و بايد قبـل از انجام مطالعه، بـا توجـه بـه تجربـه قبلى

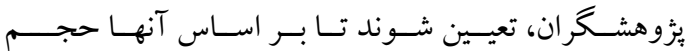

$$
\text { نمونسهة تعيين شود(V). }
$$

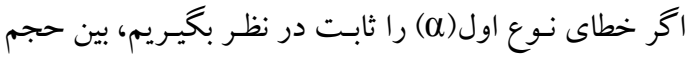

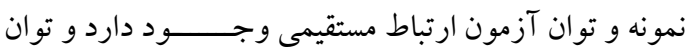
آزمون كاملا تحت تأثير اندازه نمونه مى باشد و بـراى انجـام

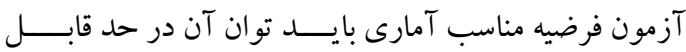
قبـولى باشد. اخـر حجـم نمونسه خيلـى كوجـك بـ باشد آزمون

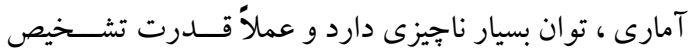
رابطه بين متغيرهاى مـــورد بررســى و يــا تفاوت بين مقدار

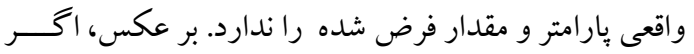
حجم نمونه بيش از اندازه بزركَ باشد، توان آزمون نزديكك به يكك خو اهد شد و در اين حالت، ازمون مورد استفاده مسى تواند هر گونه تفاوت جزيى يا ارتباط ضعيف بـين متغيرهـا را

كشف نمايد و موجب رد نادرست فرضيه صفر شود(^). اصل كلى در نمونه گيرى اين است كه هرجه نمونسه بزرگ تر باشد خطا كم تر و نتيجه به دست آمده اطمينان بخـش تر خواهـــ بـود. امـا تعيسين انـدازه يـا حجـم نمونـه در مطالعـات كوناگون به عو امل متعـددى بستخى دارد كـه ممكـن اسـت موجب بيتيديد كى فرمولهاى تعيين حجم نمونـه شـود و بـراى يزوهشخرانى كه آشنايى كافى با آمار ندارند نـامفهوم باشـد. با توجه به اينكه امروزه مطالعات مختلف توسط بروهشـخران در حوزه هاى مختلف علوم بزشكى انجام مى شود، هدف از اين مطالعه تعيين حجم نمونسه در مطالعـاتى اسـت كـه كـابرد

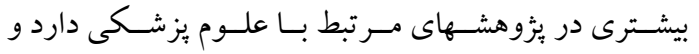
بصورت كسترده مورد استفاده يثوهشگران قرار مى گيرد.
مقدمه

هدف اصلى از انجام هر يزوهش تفسير كردن نتايج و تعمسيم نتـايج حاصـل از نمونسه بـه كـل جامعـه اسـت.نمونسه شـامل زير مجموعه ایى از جامعه است كه به نحوى انتخاب شده انــ كه معرف يا نماينده جامعه باشـند( (1). موضوع بر آورد حجم نمونه و انتخاب يكك نمونه مناسب، يكى از مسائلى است كه اكثر محققين در شروع مطالعه و يثوهش خود با آن سرو كار دارند. تعـداد كـم يـا زيـاد حجـم نمونـه يعنسى بـه هــــر دادن بودجه و منابع. مطالعه كوجّك و بـا حجـم نمونـه كـم باعث خو اهد شد تا دقت نهايى نتيجه كيرى كم باشد و بـه عبـارتى اعتماد و اعتبار نتايج زير سوال رود، لذا هزينه يرداخت شـده و امكانات صرف گرديـده اسـت ولى نتيجـه گيـرى مـوثر و . ارزشـمند بـه دسـت نخواهـد امــــ اخـر حجم نمونه كمتر از ميزان لازم در نظركرفته شود، ممكن است نتايج استنباط شده از آن در مورد جامعه از دقت كافى برخوردار نبوده و امكان تعميم نتايج حاصل از نمونه به جامعه وجود نداشته باشد. در مقابل حجم نمونه بالا نيز باعـث خـرج شـدن زيـاد بودجه مى شود، ولى افزايش دقت به اندازه هزينه اضافه شده

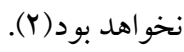
براى انتخاب حداقل حجم نمونه مورد نياز، روش هاى متعددى وجود دارد و حداقل حجم نمونه مورد نياز را بايد بر اساس اهداف اصلى تحقيق بر آورد نمود كـهـ ايـن هـدف ممكن است براورد يكك يارامتر از جامعه و يا بررسى ارتبـاط

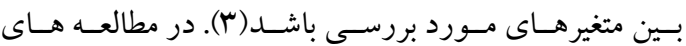
توصيفى، هدف براورد يكك ميانكين يـا يـك نسـبت اسـت و يزؤهشخران، در اين نوع مطالعه هـا سعى مسى كنــد بـر آورد مورد نظر را با دقت و اطمينان بـالايى بدسـت آورنـد(F). در مطالعات تحليلى كه طيف گسترده ای از مطالعـات در علوم بزشكى مثل مطالعات همخروهى، مورد شاهدى، تحليل بقا و كار آزمايى هاى بـالينى رادر بـر مسى گيـرد، آزمـون فرضسيه انجام مى شود و حجـم نمونـه در ايـن مطالعـات بـا توجـه بـــ آزمون آمارى مورد استفاده تعيين مى شود (ه). در يـرّوهش هاى كيفى نيز نمونـه كيـرى تـا جـايى كـه داده هـا بــه اشـباع 
تعيـين حجـم نمونـهـ ابتــا تعـداد بيشـامدهاى مـورد انتظـار را بصورت زير تعيين مى كنيم:

(1-1) $N_{E V}-\left(\frac{\left(z_{1-\sigma_{/ n}}+z_{1}-\beta\right)(\Delta+1)}{\Delta-1}\right)^{2}$

حجم نمونه نهايى را با اين فرض كـه نسـبت حجـم نمونسه در

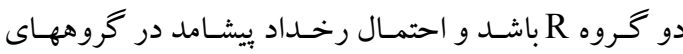
مورد بررسى به ترتيب Pو P Pاشد، بصـورت زيسر حسـاب مى شود (9) : (9) - (9)

(1-Y) $N=\frac{N_{E V}}{\frac{R}{R+1}\left(P_{2}+P_{1}\right)}$

r. حجم نمونه مورد نياز در مطالعات ارزشى تشخيصى: براى بر آورد تعداد موارد جهت تعيسين حساسيت يـا ويزگى يـك آزمسون تشخيصى جديــ از آنجـايى كـه حساسـيت و ويزز گى، يكك نسـبت هسـتند، بـراى بـر آورد حجـم نمونـه، از

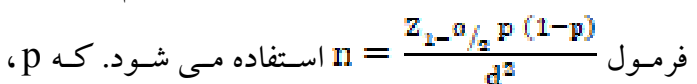
مقدار حساسيت يا ويز گیى است كه بر اساس مطالعـات قبلى تعيين مى شود. اين فرمول زمسانى كاربرد دارد كه وضسعيت بيمـارى كـاملا مشـخص باشـد. اخـر شـيوع بيمـارى كـاملا مشخص نباشد و يا مثلا از افرادى كه بصورت متـوالى مـورد

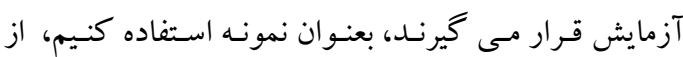
فرمولهاى ديخرى استفاده مى كنيم. عملا بز شكان علاقه مند

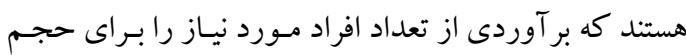
نمونه بر اساس حساسيت و ويز گى، زمانى كه جمعيت مـورد مطالعه شامل موارد (Cases) و شاهد ها (Controls) است، بدست آورند. در اين حالت، بايد نسبت مـوارد و شـاهدها و

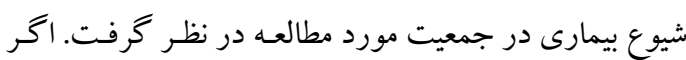
ncases تعداد موارد، ntotal تعداد كل (موارد و شـاهدها)، و Prev شـيوع بيمـارى باشــد، آنخـاه بـر اسـاس حساسـيت،

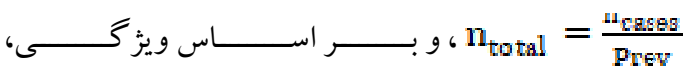
و $n_{\text {total }}=\frac{n_{\text {gontrola }}}{1-p_{\text {rev }}}$ ويز گیى را مدنظر قراردهيم، از فرمولى استفاده مى كنيم كـه بيشترين حجم نمونه را محاسبه كند. جنانجه تعـداد مـوارد يـا
مواد و روشها در ايسن مطالعـه بــه بررسـى روشـهاى تعيـين حجــم نمونسه درمطالعات مرتبط با علوم بزشكى برداختـه ايسم. ابتـدا انواع مطالعات قابل انجام در حوزه علوم يزشكى دسته بندى شدند و مطالعاتى كه امـروزه كـاربرد بيشـترى دارنـد تعيـين شـدند. يس از تعيين مطالعات، در منـابع مختلـف داخلـى و خـارجى (كتابها، مجله ها، مقالات و ...) و يايخاههـاى مختلفى جـون ، Scopus و ISI (Web of Knowledge) ، PubMed بر اساس كليد وازه حجم نمونه و توان آزمون جستجو انجـام شد و روشهاى مختلف تعيين حجم نمونه همراه با فرمولهاى مربوطـه اسـتخراج و دسـته بنـدى شــند. از بـين روشـهاى مختلف با توجـه بـه نـوع مطالعـه و سـاير عوامـل تاثير خـذار، بهترين فرمول و روش، استخراج شد. مطالعاتى كه براى آنها حجم نمونسه تعيسين شـدند عبارتنـد از

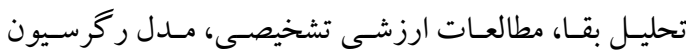
خطسى، رگر ســيون لجسـتيك، آنـاليز واريــانس، آنـاليز كواريانس، مطالعات تحليل عاملى و مدلهاى ساختار يافته. با توجه به اينكه مطالعه از نوع علوم يايه است آزمون آمـارى خاصى استفاده نشده است. اما در عين حال براى هر كـدام از روشهاى مورد بررسى كه ذكر شده است، بـر اسـاس خطساى نوع اول، توان آزمون، دقت بـر آورد، تعـداد يار امترها،تعـداد متغيرها، و ساير يارامترهايى كه ممكن است تاثير كذار باشند فرمول حجم نمونه تعيين شده است.

نتايج ا.حجم نمونه مورد نياز در تحليل بقا: بـراى تعيسين حجـم نمونـه در مطالعـات بقـا، سـه عنصـر مهـم

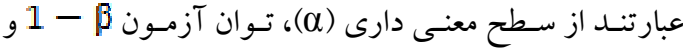

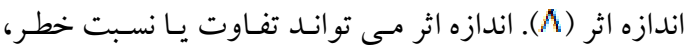

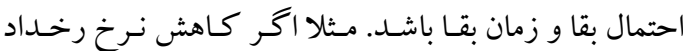

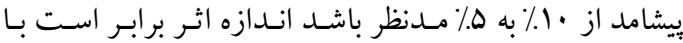
إل $=2$ مدنظر باشد انـدازه اثـر برابـر اسـت بـا $2=\frac{14}{7}=2$. 
كه منحنى هاى مربو طه بازاى هاى آزادى مختلف در دسترس مى باشند. اخر و و واريانس نيز بر اسـاس تجرييات قبلى و يا يكك آزمايش اوليه تعيين مى شود.

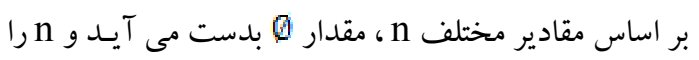

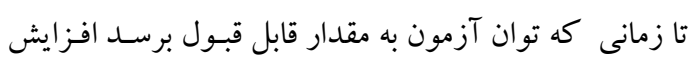
مى دهيم(1) 9.حجم نمونه مورد نياز در آناليز كواريانس:

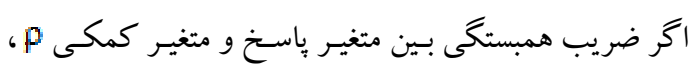

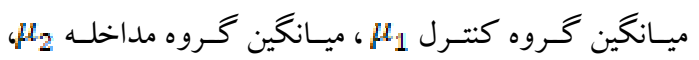

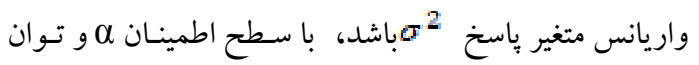

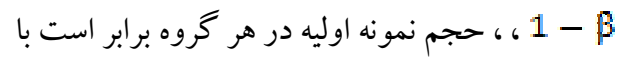
$n=2 \frac{\left(Z_{1-\alpha / 2}+Z_{1-\beta}\right)^{2} * \sigma^{2}}{\left(\mu_{1}-\mu_{2}\right)^{2}}$ و حجم نهايى نمونه برابر است با (1) (1):

$$
N=2(n+1)\left(1-\rho^{2}\right)
$$

V Vحم نمونه مورد نياز در مطالعات تحليل عاملى:

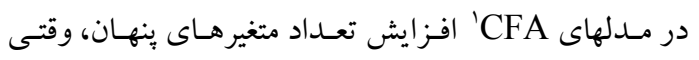

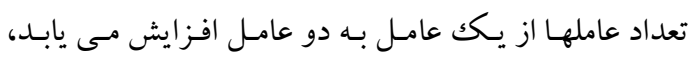

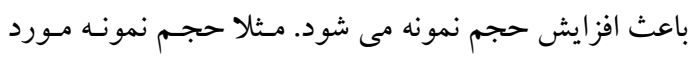

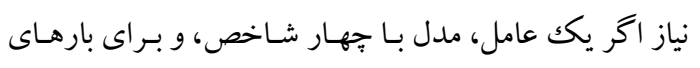

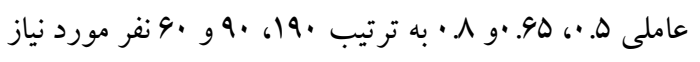

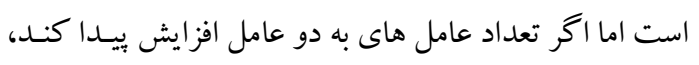

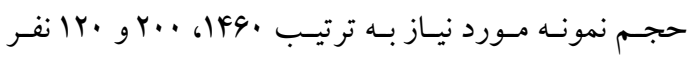

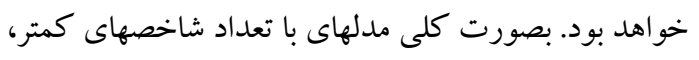

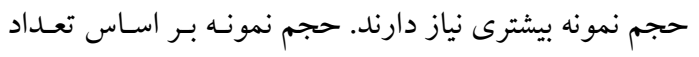

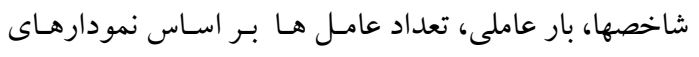
زير تعيين مى شود (1ه):

\footnotetext{
${ }^{1}$ Confirmatory factor analysis
}

شاهدها نامعلوم باشد مى توان با استفاده از بر آورد حساسيت

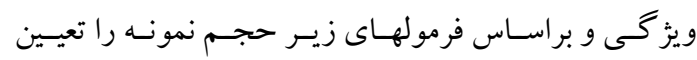
كرد)

$(r-1) n_{S_{p}}=\frac{z_{1-} \alpha_{j s} \widehat{s p}(1-\widehat{S p})}{\hat{d}^{3} * p_{\text {rev }}}$

$$
\text { r.حجم نمونه مورد نياز در مدل رگر سيون خطى: }
$$

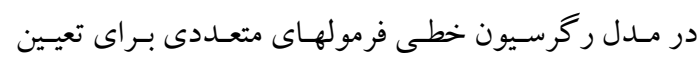

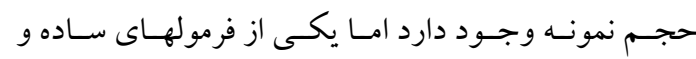

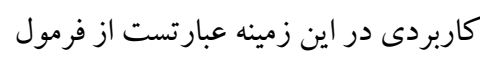
(r-1) $n=\frac{\left(z_{1-\alpha_{\beta}}+z_{1-\beta}\right)^{2}}{f^{2}}+K+1$ كه در اين فرمول، k تعداد متغيرهاى مستقل و f مقدار اندازه

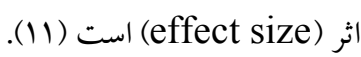

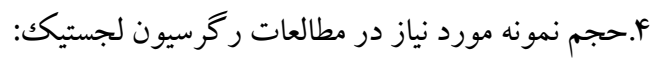

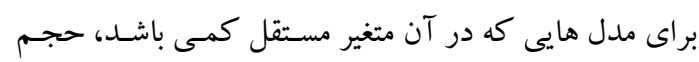

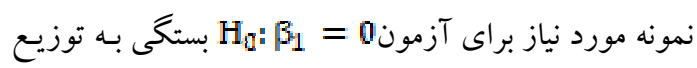

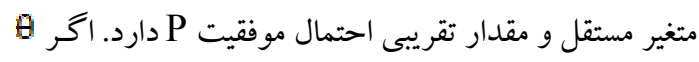
نسبت شانس و (e)

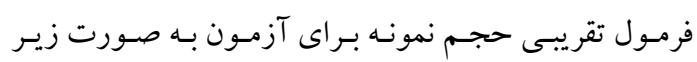

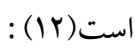

$$
n=\left[z_{\alpha}+z_{\beta} \exp \left(-\frac{\lambda^{2}}{4}\right)\right]^{2}(1+2 \mathrm{P} \delta) /\left(\mathrm{P}^{2}\right)
$$

$$
\begin{aligned}
& \delta=\left[1+\left(1+\lambda^{2}\right) \exp \left(5 \lambda^{2} / 4\right)\right] /[1+ \\
& \left.\exp \left(-\lambda^{2} / 4\right)\right] \\
& \text { ه.حجم نمونه مورد نياز در آناليز واريانس: }
\end{aligned}
$$

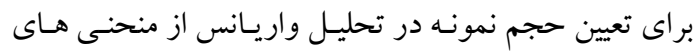

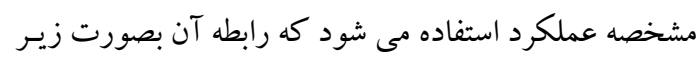

$$
\begin{aligned}
& \phi^{2}=\frac{n \sum_{i=1}^{a} \tau_{i}^{2}}{a \sigma^{2}}
\end{aligned}
$$



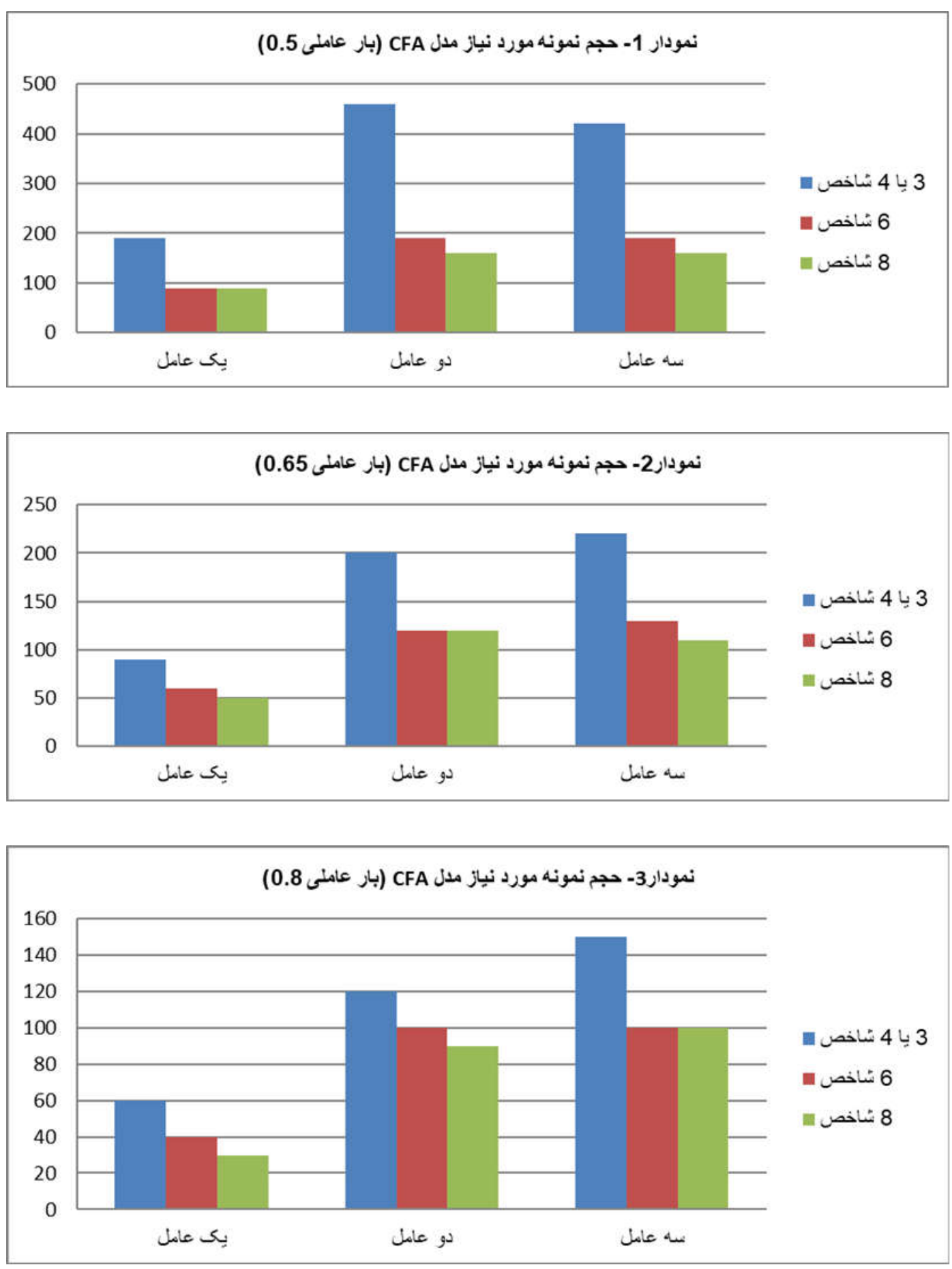


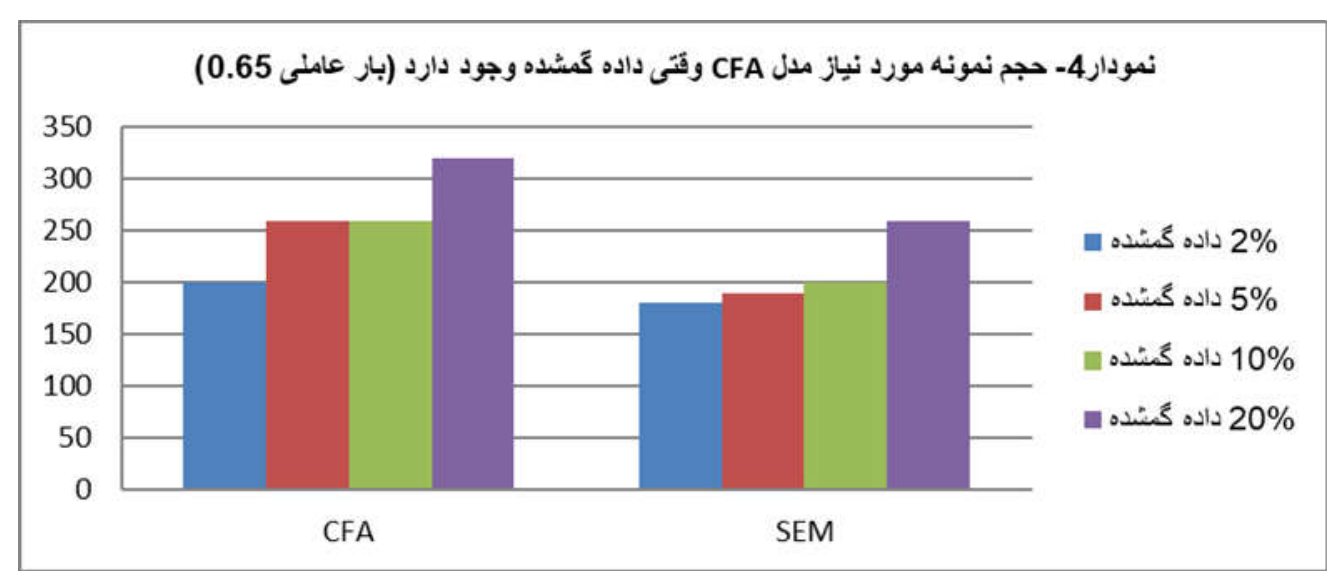

مهمى دارد كه در فرمول (F-1) ارائه شده است. در رگرسيون لجستيك نيز برخى إزوهشخران مطالعاتى براى دورد

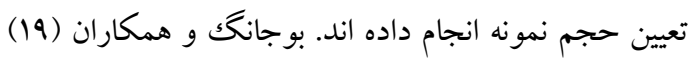

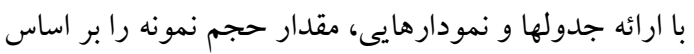
متغيرهاى مورد بررسى وشر ايط مختلف مطالعه ارائه داده اند.

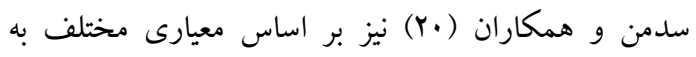

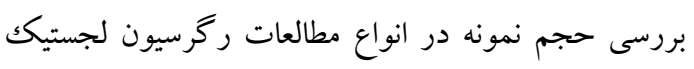
يرداخته اند كه نسبت به فرمول ارائه شده در اين مطالعه شامل معيارهاى بيجيجيده ترى مى باشد.

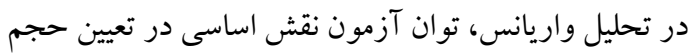

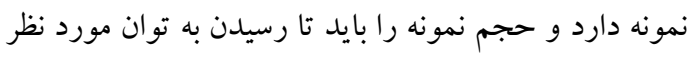

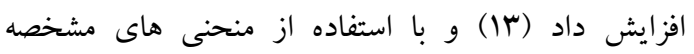
عملكرد مى توان از كفايت حجم نمونه مطمئن بود كه در

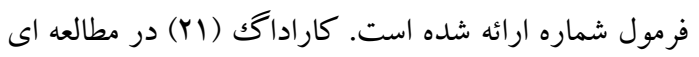
به تعيين حجم نمونه در مطالعات مختلف تحليل واريانس برداخته است و با استفاده از نمودار و جدولهايى حجم نمونه بهينه را بر اساس توان آزمون، سطح معنى دارى و اندازه اثر إن

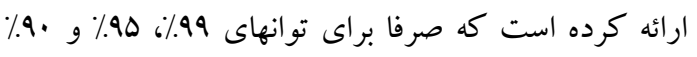

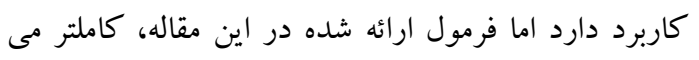
باشد و براى توانهاى مختلف كاربرد دارد. ماهايونيانون و

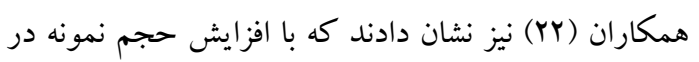
تحليل واريانس، توان آزمون بيشتر مى شود. اخر متغير مورد مطالعه زمان تا رخداد يك حادثه باشد از روش تحليل بقا استفاده مى شود(9). براى تعيين حجم نمونه

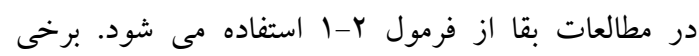

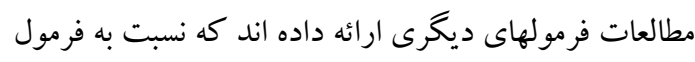
فوق بيجيجده تر است، نياز به محاسبات بيشترى دارد و بويزه زمانى كاربرد دارد كه از مدل كاكس در تحليل استفاده

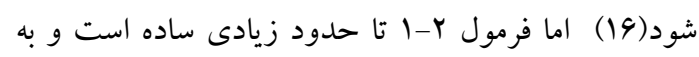
راحتى براى مطالعات مختلف بقا، كاربرد دارد.

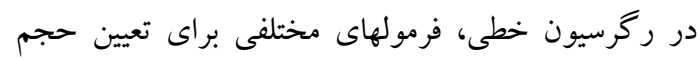

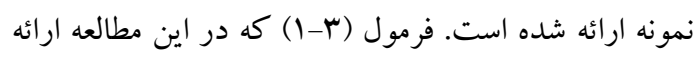

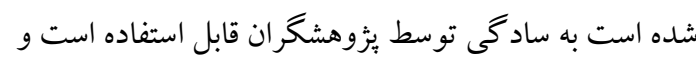

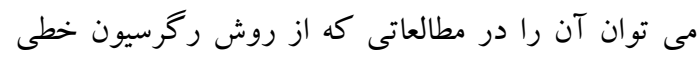

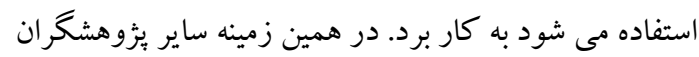
از جمله جان و همكاران (IV) فرمولهاى كاملى ارائه داده اند

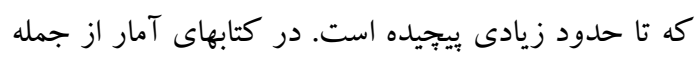
مونتخمرى (IN) هم براى تعيين حجم نمونه و انجام آزمون

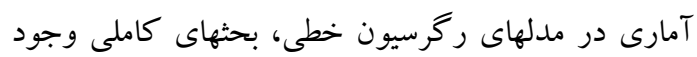

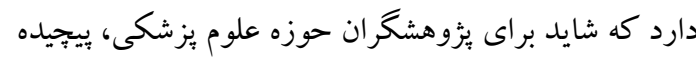
باشد. در مطالعاتى كه متغير وابسته كيفى باشد از ركرسيون لجستيك براى تحليل داده ها استفاده مى شود و و در بـانئه رگرسيون لجستيك نسبت شانس در تعيين حجم نمونه نقش 


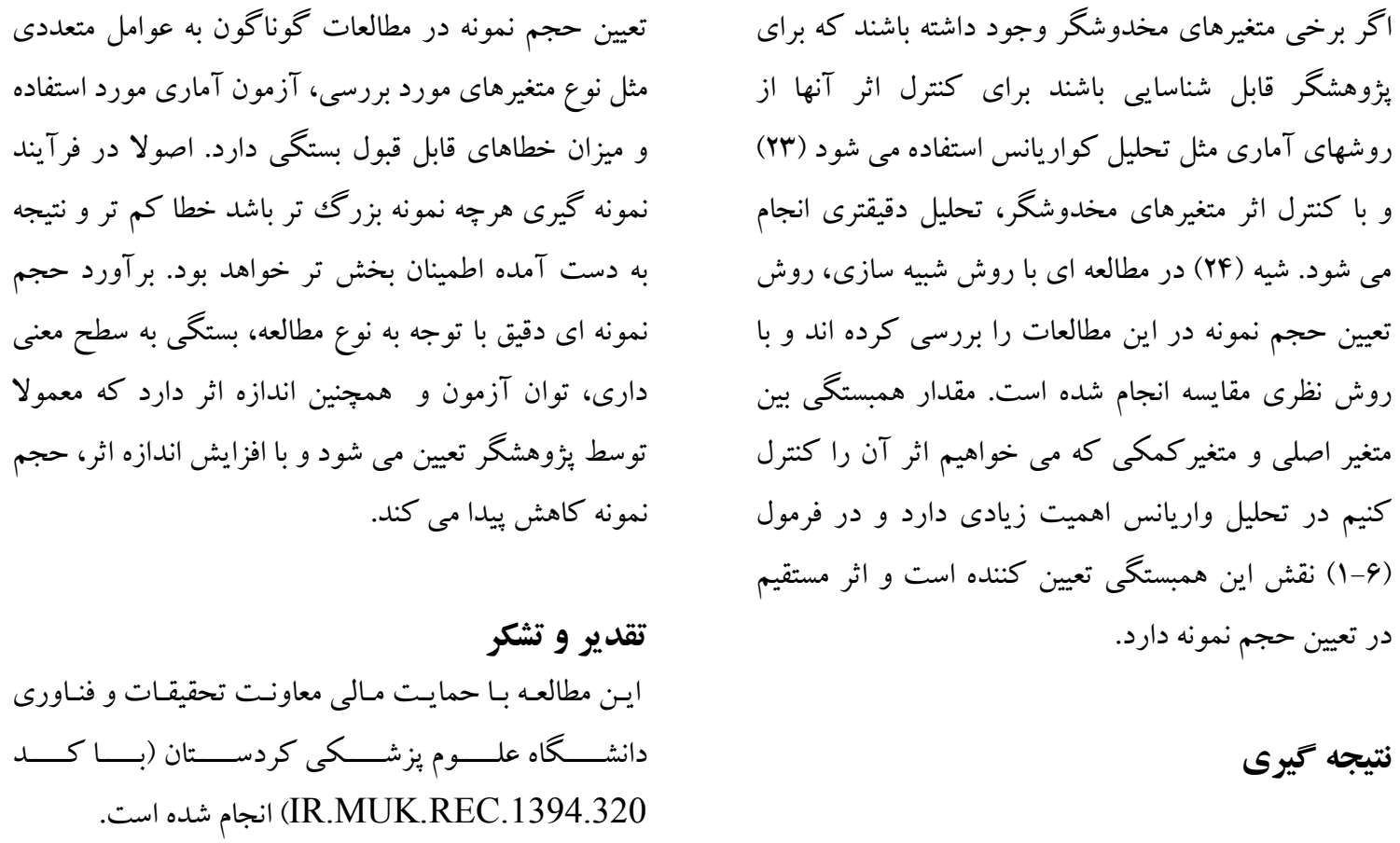

(IR.MUK.REC.1394.320) انجام شده است.

\section{منابع}

1.Ali A. Sampling Theory and its Application. 5, editor. Tehran: Nashre Daneshgahi; 2009.

2.Jones $\mathrm{S}$, Carley S, Harrison M. An introduction to power and sample size estimation. Emerg Med J. 2003;20(5):453-458.

3.JabariNoghabi H, JabariNoghabi e. Thoughts on the sample size and presentation software. College student Statistics (NEDA). 2007;4(2):13-21.

4.Haghdoost A-A. Do you want to test the sample and deeper understanding? IRJE. 2009; 5 (1) :57-63.

5.Thompson SK. Adaptive cluster sampling. J Am Stat Assoc. 1990;85(412):1050-9.

6.Ranjbar H, Haghdoost A-A, Salsali M, Khoshdel A, Soleimani M, Bahrami N. Sampling in qualitative research: A Guide for beginning. HBI_Journals. 2012;10(3):238-50.

7.Warwick DP, Lininger CA. The sample survey: Theory and practice.1st ed. New York: McGraw-Hill, 1975;120-50.

8.Cochran WG. Sampling techniques: John Wiley \& Sons; 2007.

9.Kleinbaum DG, Klein, Mitchel. Survival Analysis A Self-Learning Text. Edition T, editor: Springer; 2012.

10.Hajian-Tilaki K. Sample size estimation in diagnostic test studies of biomedical informatics. J Biomed Inform. 2014;48:193-204.

11.Cohen J, Cohen P, West SG, Aiken LS. Applied multiple regression/correlation analysis for the behavioral sciences.3rd ed. Oxfordshire:Routledge, 2014; 151-90.

12.Agresti A. Categorical data analysis.2nd ed. New Jersey: John Wiley and Sons,Inc, 2002: 211-57.

13.Montgomery DC. Design and analysis of experiments. 6th ed. Tehran: Iran University of Sceince and Technology, 2017; 176-84. 
14. Shan G, Ma C. A Comment on sample size calculation for analysis of covariance in parallel arm studies. J Biomet Biostat. 2014;5(1):1.

15.Wolf EJ, Harrington KM, Clark SL, Miller MW. Sample size requirements for structural equation models: An evaluation of power, bias, and solution propriety. EPM. 2013;73(6):91334.

16.Hsieh F, Lavori PW. Sample-size calculations for the Cox proportional hazards regression model with nonbinary covariates. Contr Clin Trials. 2000;21(6):552-60.

17.Jan S-L, Shieh G. Sample size calculations for model validation in linear regression analysis. BMC Med Res Methodol. 2019;19(1):54.

18.Montgomery DC, Peck EA. Introduction to Linear Regression Analysis. 3, editor. Kerman: Shahid Bahonar University of Kerman; 2007.

19.Bujang MA, Sa'at N, Bakar TMITA. Sample size guidelines for logistic regression from observational studies with large population: emphasis on the accuracy between statistics and parameters based on real life clinical data. The Malaysian journal of medical sciences: MJMS.2018; 122:(4)25;2018

20.Van Smeden M, Moons KG, de Groot JA, Collins GS, Altman DG, Eijkemans MJ, et al. Sample size for binary logistic prediction models: beyond events per variable criteria. Stat Methods Med Res. 2019;28(8):2455-74.

21.Karadag Atas O, Aktas Altunay S. Optimal sample size determination for ANOVA designs. IJAMAStatistics. 2011;25:127-34.

22.Mahapoonyanont N, Mahapoonyanont T, Pengkaew N, Kamhangkit R. Power of the test of one-way Anova after transforming with large sample size data. Procedia-Social and Behavioral Sciences. 2010;9:933-7.

23.Poukak SJ. Clinical trials:A practical apporach. Shiraz: Shiraz University of Medical Sciences; 2001.

24. Shieh G. Power Analysis and Sample Size Planning in ANCOVA Designs. Psychometrika. 2019;1-20. 